likely to be in assessment of the effectiveness of treatment. Often enough the treated hypertensive feels less well than he did untreated, and this may be as much a tribute to the wellbeing of many hypertensives as it is a condemnation of the drugs that have been prescribed.

Far too many hypertensives come to light with serious complications for doctors to have any confidence in existing methods of diagnosis. As the trend towards occupational and preventive medicine grows, and as the public come to accept the idea of maintenance of health, doctors will have to clarify their attitudes to hypertension in the symptomless stage. Fortunately, drugs are now becoming available that appear to be exceptionally well tolerated and which may be effective, on the blood pressure at least, in the milder hypertensives on whom interest is now focusing. For such patients decisions should not be based simply on casual readings of blood pressure or non-specific symptoms. When the true blood pressure is known, and when remediable causes have been excluded, drug treatment should aim to be as symptomless as the disease, and it will probably be adjusted in the light of the pressure recorded rather than because of vague and untrustworthy symptoms.

${ }^{1}$ Harington, M., Kincaid-Smith, P., and McMichael, J., British Medical fournal, 1959, 2, 969.

2 Leishman, A. W. D., Lancet, 1963, 1, 1284.

3 Freis, E. D., et al., Fournal of the American Medical Association, 1967, 202, 1028.

Smirk, F. H., Antihypertensive Therapy, ed. F. Gross, p. 355. New York,

Springer, 1966.
${ }^{5}$ Breckenridge, A., Dollery, C. T., and Parry, E. H. O., Quarterly fournal of Medicine, $1970,39,411$.

6 Ayman, D., and Pratt, J. H., Archives of Internal Medicine, 1931, 47, 675.

Stewart, I. M. G., Lancet, 1953, 1, 1261.

8 Badran, R. H. A., Weir, R. J., and McGuiness, J. B., Scottish Medical Fournal, 1970, 5, 48.

O Robinson, J. O., Fournal of Psychosomatic Research, 1969, 13, 157

10 Weiss, N. S., New England Fournal of Medicine, 1972, 287, 631.

11 Mitchell, J. R. A., British Medical fournal, 1959, 1, 25.

\section{Care of Elderly People with Dementia}

The Department of Health and Social Security has followed its memorandum on hospital services for the mentally ill (HM(71)97) with a further memorandum giving guidance on services for mental illness related to old age (HM(72)71). This memorandum complements reports on the same subject which have already been published by the Scottish Home and Health Department ${ }^{1}$ and the Northern Ireland Health Authority. ${ }^{2}$ It will be welcomed by all physicians and psychiatrists who are at present attempting to provide services for old people with mental illness.

The memorandum identifies various groups of elderly people with mental illness and suggests how they should be treated. Those patients with mental illness who have grown old in mental hospitals are, it suggests, a declining group but one whose numbers remain substantial. These patients are to be left in surroundings familiar to them, when that is possible, but efforts will be made to provide them with a full life, and they will be kept under constant review in case further rehabilitation and discharge from hospital can be offered. Presumably these patients will remain the responsibility of the therapeutic teams referred to in the earlier memorandum (HM(71)97), but it will be important to ensure that they are not overlooked. Elderly persons with functional mental illness will not be treated separately from younger patients with similar illness and will be dealt with by the mental illness department of district general hospitals.

The major part of memorandum $\operatorname{HM}(72) 71$ deals with elderly persons with dementia. It does not suggest any major change in the present broad division of work between psychiatrists and physicians in geriatric medicine. Elderly people with dementia and physical disease will continue to be cared for in geriatric beds under the care of the physician in geriatric medicine, while elderly persons with severe dementia and behaviour disorders - will continue to be cared for by a psychiatrist. Though it notes that psychiatrists with special responsibility for psychiatric services to the aged have been appointed in some areas, the memorandum makes no specific recommendation to create a specialist "psychogeriatrician." The general practitioner's contribution in hospitals serving local communities is rightly considered to be valuable.

The work of voluntary organizations is stressed, and the family too has an important part to play, for if it receives adequate support from day hospitals a mildly demented patient can often be managed for long periods at home. The existence of experimental local arrangements, such as the appointment of geriatric liaison health visitors and a domiciliary psychiatric nursing service for the elderly, are helpful. In fact domiciliary psychiatric nursing services for the elderly are essential if adequate support is going to be given to patients and relatives at home. The memorandum notes the importance of close co-operation between psychiatrists and physicians in geriatric medicine. Indeed it is essential, and contractual sessions for both types of consultant in each other's specialty should always be strongly encouraged.

In laying down guide lines for hospital and local-authority places, the memorandum suggests that 2.5 to 3 beds and 2 to 3 day places per 1,000 population aged 65 and over should be provided within the hospital setting. Some beds will be in general hospitals but most perhaps in relatively small hospitals serving local communities. Local authorities, it says, should make an overall provision of 25 residential places per 1,000 elderly people. This is 3 places per 1,000 higher than the current national "norm," and it is to be hoped that these places will be provided in separate units and that some day places will be provided.

While the provision of a large number of hospital day places is to be welcomed, the suggested provision for inpatients and residential care may be insufficient. At present there are approximately $2 \cdot 2$ mental hospital beds per 1,000 total population. In most mental hospitals half of the beds are occupied by patients over the age of 65 , and about half of these are occupied by elderly persons with dementia. This represents a bed provision of about 7.5 beds per 1,000 aged over 65 , a figure above the proposed future combined hospital and local-authority provision. The memorandum states that the population aged 75 and over will increase by more than $18 \%$ in the next decade. The incidence of senile dementia over the age of 75 is about $13 \%$, and this means there would be between 50,000 and 60,000 additional cases of dementia per annum in ten years' time. To cater for $10 \%$ of these in hospital would require about 6,000 additional beds. $^{2}$ Since the existing services are unable to meet the current demand, the outlook for the future looks pretty grim. Thus, though the memorandum is a stride in the right direction, it does not advocate nearly enough.

1 Scrttish Home and Health Department, Scottish Health Services Council, Services for the Elderly with Mental Disorder. Edinburgh,

2 Ministry of Health and Social Services, Geriatric and Psychiatric Services for the Elderly: Redort of a Subcommittee of the Standing Medical Advisory Committee for Northern Ireland. Belfast, H.M.S.O., 1970 . 